\title{
El mediador cultural en los servicios públicos: una nueva profesión
}

\author{
RAQUEl SANTANA FALCÓN \\ Universidad de Sevilla \\ raquel.santana.trad@gmail.com
}

Recibido: 7 de diciembre de 2012

Aceptado: 5 de marzo de 2013

\section{RESUMEN}

El presente artículo pretende abordar la necesidad de consagrar la intermediación cultural en los servicios públicos como una nueva profesión ligada a la interpretación. Para ello, se hará especial hincapié en el papel que desempeña el intérprete como mediador en la sociedad multicultural, cuáles son sus características intrínsecas y sus necesidades. Además, se expondrá el estado actual de la mediación en España y los modos de intervención con la población inmigrante pese a los escasos instrumentos de los que se dispone.

Palabras clave: sociedad multicultural, servicios públicos, mediación intercultural, el intérprete como mediador.

The cultural mediator within public services: a new profession

\begin{abstract}
The purpose of this article is to raise the necessity of establishing cultural mediation in the public sector as a new profession linked to interpreting services. Therefore, we shall emphasise the role of the interpreter as a mediator in multicultural societies, as well as their intrinsic characteristics and needs. Furthermore, the situation of mediation in Spain will be presented and analysed, including examples of how mediation with immigrant population is dealt at the moment despite the lack of resources.
\end{abstract}

Keywords: multicultural society, public services, cultural mediation, the interpreter as mediator.

Sumario: 1. Introducción. 2. Necesidades concretas de los intérpretes de los SSPP. 3. ¿Estamos ante una nueva profesión? 4. ¿Qué es mediar? 5. La figura del intérprete como mediador 6. Mediación intercultural: ámbito profesional 7. Conclusión. 


\section{Introducción}

Nuestro principal objetivo en este artículo consiste en demostrar que la interpretación en los Servicios Públicos (SSPP) posee una serie de características que la hacen muy diferente de otras modalidades de interpretación y, por ende, debe consagrarse como una profesión. El intérprete puede encontrarse con situaciones comprometidas que le obliguen a tomar decisiones sobre su actividad. De este modo, deja de ser un autómata, se humaniza, y se convierte en un agente social, asumiendo la responsabilidad de mantener activa la comunicación entre sus clientes (con lenguas y culturas distintas) y de procurar que esta sea efectiva, limando desigualdades entre ellos y situándolos al mismo nivel social. Ello conlleva tener un conocimiento histórico, social y cultural sobre los interlocutores. Y habría que puntualizar que parte de este conocimiento cultural es saber cómo funcionan las instituciones públicas o los sistemas administrativos, educativos, sanitarios, sociales, etc. de los países de los clientes.

En este sentido, se observa un progresivo, aunque lento, reconocimiento de que el avance hacia sociedades multiculturales provoca una serie de necesidades y expectativas que hay que cubrir. Es cada vez más evidente el interés creciente por este tipo de traducción e interpretación, considerado como un mecanismo más para facilitar la comunicación entre la población mayoritaria y aquellas personas con un conocimiento limitado de la lengua de la mayoría o de la lengua que utilizan en los SSPP.

\section{Necesidades concretas de los intérpretes de los SSPP}

Las sociedades son cada vez más conscientes de la realidad multicultural, que se va configurando y va dando sus primeros pasos en una cuestión descuidada hasta ahora, la mediación intercultural.

Muchos inmigrantes, refugiados o ciudadanos ilegales traen como único equipaje su lengua nativa y sus tradiciones y costumbres, que son, así mismo, desconocidas por los habitantes del país de acogida. Tal situación conlleva una serie de problemas que los diferentes gobiernos y la misma sociedad trata de resolver con medidas irregulares, laborales, sociales, o simplemente, de convivencia. Porque uno de los problemas con frecuencia olvidado, a pesar de la sensibilización que existe en la Unión Europea sobre la diversidad de lenguas, es la comunicación interlingüística.

Considerando que los conocimientos de estas personas sobre la lengua del país de acogida (sobre todo cuando llegan), son escasos o muy limitados y tienen que enfrentarse a situaciones (en el hospital, la escuela, la policía, oficinas del estado, etc.) en las que su uso es necesario y sus interlocutores muy diferentes, es fácil adivinar que los gobiernos y las instituciones de los diferentes países deben tomar conciencia de esta realidad y aportar soluciones diversas y urgentes, a veces simplemente locales.

Cuando el estado o la institución no provee tales instrumentos para hacer efectiva la comunicación, la propia población extranjera, las organizaciones o perso- 
nas que les ayudan buscan intermediarios entre sus amigos, parientes e incluso sus hijos que, aunque menores de edad, dominan la nueva lengua mejor que sus progenitores. En el caso en que sea el estado el que proporcione la ayuda ante una situación nueva y urgente para la que no cuenta con mecanismos, suele confiar con frecuencia esta tarea a las ONG. Así ocurre en España, donde son tales organizaciones las que, en definitiva, prestan una mayor ayuda a los inmigrantes y refugiados en cuestiones de asesoría judicial, social, laboral, jurídica o lingüística a través de listas de personal, muchas veces voluntario, a las que recurre. Prácticamente todos ellos han servido de enlaces con amigos y parientes de forma voluntaria y, cuando se trata de un trabajo remunerado, un $25 \%$ de los encuestados dice que lo consiguió a través de alguna ONG. El 50\% trabaja o ha trabajado para ONG, servicios o instituciones públicas (hospitales, escuelas, oficinas del estado) y suelen realizar o han realizado tareas de ayuda voluntaria, frecuentemente con inmigrantes y, en menor proporción, con refugiados. De ellos, un $2 \%$ había completado estudios universitarios en sus países de origen, y el resto había cursado algún taller o seminario en la Escuela de Traductores de Toledo o en la EMSI. El resto no había recibido ninguna instrucción como traductores o intérpretes y contaban como único bagaje con su experiencia con familiares, amigos, personas del mismo grupo étnico o voluntariado en ONG y otros organismos de la ayuda humanitaria, aunque todos ellos consideraban necesaria la formación (Valero 2006).

Esta es la realidad social de muchos países del mundo occidental, entre ellos España, que se halla en un proceso de cambio que plantea nuevos interrogantes, puesto que en este ámbito se carece de formación para españoles.

Sin embargo, en el terreno exclusivamente lingüístico, en todos los países suelen existir figuras consideradas oficiales como son el traductor jurado o el traductor del Ministerio del Interior o del Ministerio de Justicia, en el caso de España. Ahora bien, las lenguas en las que prestan sus servicios y su preparación están, a veces, muy lejos de las verdaderas necesidades que hay que cubrir. Con frecuencia los recién llegados no traen una sola lengua sino diferentes dialectos que hacen más difícil su comunicación con el gobierno y la sociedad española, poco acostumbrados a estas variedades lingüísticas. Una de las consecuencias más evidente la hallamos en la disponibilidad de intérpretes y traductores en los SSPP para aquellas lenguas que hasta hace muy poco eran prácticamente desconocidas. Como resultado, la traducción e interpretación se ve marcada por ciertos condicionantes, entre los que destacaría:

- La falta de formación adecuada y de conocimientos sobre la ética de la profesión y sobre términos legales o especializados de muchos intérpretes;

- Los procedimientos, en ocasiones poco adecuados, utilizados por las oficinas de los servicios públicos para aceptar a los intérpretes;

- La falta de directrices claras sobre la actuación de estos intérpretes;

- La realización de malas traducciones o interpretaciones defectuosas que pueden privar a las minorías de sus derechos. 


\section{3. ¿Estamos ante una nueva profesión?}

Queda reconocida la enorme variedad entre los países en la provisión, formación y acreditación de los traductores e intérpretes que trabajan y colaboran con los SSPP (Mary Phelan 2001: 20-38; Valero 2003: 3-30; Corsellis 2003: 180-191), por ejemplo, unos lo han hecho a nivel nacional y otros a nivel local. Algunas organizaciones prestan servicios multilingües gratuitos y otras los cobran. Hay gobiernos que financian los servicios de T/ISSPP mientras que en otros los apoyan indirectamente o los ignoran casi por completo.

Algunos países han desarrollado estrategias para organizarse y proporcionar esos servicios a los grupos o personas que necesitan de asistencia lingüística mientras que otros están ahora empezando a ver el problema. En algunos países existe formación universitaria mientras que en otros se reducen a talleres, jornadas y cursos de un número variable de horas.

Este panorama tan variado hace difícil, como ya indicaba Pöchhacker (2002: 125-141), mantener la unidad en la diversidad. Sin embargo, una visión global de la situación puede llevarnos a vislumbrar algunas tendencias y avances en la T/ISSPP aún cuando ello no quiera decir que podamos hablar de globalización, término usado en exceso y desde las más variadas posiciones y con significados incluso contradictorios. En el terreno en el que nos movemos no parece, sin embargo, tener cabida el concepto de globalización, puesto que, en lugar de ir hacia posiciones de entendimiento más generales, el efecto parece ser el contrario: mayor diversidad, gran variedad de lenguas y culturas en un espacio muy reducido, desconocimiento de las partes, falta de tiempo para asimilar cambios, diferencias sociales importantes, etc.

Los practicantes de la T/ISSPP coinciden en señalar que existen varias etapas en el proceso hacia la comunicación efectiva y real en sociedades multiculturales con minorías que desconocen o no conocen lo suficiente la lengua y cultura de la mayoría.

Corsellis (2002: 182-186) menciona tres procesos que se desarrollan de forma consecutiva, cada uno de los cuales se refiere a uno de los eslabones que forman parte de la cadena de la comunicación. Estos son: 1) los proveedores de servicios públicos; 2) los usuarios de los SSPP que no dominan la lengua en la que se ofrecen esos servicios; 3) los intermediarios que hacen posible la comunicación.

\section{4. ¿Qué es mediar?}

Nos encontramos con frecuencia ante personas que podríamos considerar bilingües y que desempeñan el trabajo de un intérprete o un traductor. Entraríamos así en la discusión de si ser bilingüe equivale a ser traductor o intérprete. La literatura sobre este aspecto es amplia y resulta imposible condensarla en unas páginas, sin embargo, existe un acuerdo bastante generalizado en que no son sinónimos. No toda persona que domina dos lenguas es necesariamente traductor o intérprete. 
Una vez aclarado este punto, surge otro más específico en relación con el papel que estos intermediarios lingüísticos desempeñan en nuestra sociedad. Y de nuevo tropezamos con la discusión sobre el modelo que surge (Wädensjö 1998, Mason 1999, Cambridge 2003).

Se han sistematizado dos tendencias: 1. Modelo abogacía y 2. Modelo imparcialidad. El primero, y aunque se refiere al ámbito sanitario, Cambridge (2002: 119123) lo define del siguiente modo: "En el modelo abogacía el intérprete está presente para, literalmente, abogar de parte del paciente; toma partido, hace preguntas propias, aconseja al paciente y ofrece su opinión personal sobre los temas tratados durante el transcurso de la visita". Y a continuación advierte de los riesgos que entraña, tales como omitir y dar información en exceso, no ser imparcial, crear confusión al cambiar del rol de intérprete al de abogado, asumir tareas que no le correspondan, etc.

Por otro lado, en el modelo imparcial, según Cambridge (2002: 119-123), "el intérprete, igualmente imparcial, repite todo lo que oye y todas las partes integradas a la conversación hablan con voz propia, entendidos en cada momento por los demás. El papel del intérprete consiste en convertirse en el alter ego -es decir, el otro ser- de la persona cuyas palabras está interpretando. Si lo consigue, cada uno puede decir, con energía, las palabras y las emociones que quiera, exactamente como lo diría si la interpretación no hiciera falta".

El intérprete se convierte, pues, desde esta posición en el alter ego, en la imagen del hablante capaz de trasmitir el mismo mensaje y producir el mismo efecto que el hablante mismo. Según Cambridge, ello también implica detenerse para aclarar información implícita que no sería necesario explicitar con interlocutores que comparten la misma herencia cultural. Cuatro son los motivos por los cuales el intérprete debe detener su intervención y pedir ayuda de los interlocutores:

- Porque a un interlocutor no se le oye bien;

- Porque un interlocutor ha dicho algo que el intérprete no entiende;

- Porque, a pesar de sus mejores esfuerzos, el intérprete cree que existe un malentendido;

- Porque el significado cultural de algo dicho no ha sido notado o entendido.

En estas situaciones el intérprete indica claramente el deseo detenerse y por qué, $\mathrm{y}$, a continuación, rectifica el problema. Ello indica de nuevo un cambio de rol, y vuelve a interpretar cuanto antes, para no estorbar el flujo de ideas de los demás interlocutores.

Wadensjö (1998: 102) habla también de dos modelos de interpretación, o mejor dicho, de dos papeles que el intérprete puede desempeñar y que no son excluyentes, sino más bien complementarios en determinadas situaciones como en el caso de la interpretación bilateral; y los llama relaying others' talk y co-cordinating others' talk. El primero coincidiría con el modelo imparcial de Cambridge, en el que el intérprete es invisible, y el segundo con el modelo de abogacía, en el que el desarrollo de la entrevista se ve influido por el intérprete, sobre todo, cuando lo que escucha en la LO no se comparte en la LL. 
En general, parece existir acuerdo en la necesidad de que debe darse una preparación y de que el intérprete ha de dominar una serie de técnicas que faciliten y garanticen la calidad de su trabajo, así como la necesidad de observar un código o unos principios éticos, como ocurre con cualquier profesión.

Los datos expuestos en las páginas anteriores ponen de manifiesto algunos de los problemas y riesgos que surgen cuando se trabaja con personas que carecen de formación específica. Resulta difícil decidir sobre el modelo más adecuado para los mediadores culturales, que cuentan con una serie de características añadidas a las ya tradicionalmente asignadas al traductor o intérprete considerado profesional. No obstante, habría que definir en primer lugar el papel del mediador interlingüístico.

Inmediatamente surgen preguntas: ¿es el mediador interlingüístico un traductor o intérprete? O bien, ¿se cataloga al traductor o intérprete como un mediador? O dicho de otra forma: ¿es la traducción/interpretación una de las varias tareas que desempeña el mediador? ¿Se precisa considerar al mediador un mero traductor/ intérprete dentro de los límites tradicionales de adecuación y aceptabilidad? O bien, ¿es necesario ampliar esos límites y otorgar otras funciones al mediador para ser considerado un traductor/intérprete? ¿Estamos ante una nueva figura de traductor? El resto supone encontrar el punto justo de visibilidad de estos intermediarios.

El término "mediador cultural" como persona que sirve de puente entre lenguas y culturas es utilizado por Boechner (1981) en el libro The Mediating Person and Cultural Indentity. No se trata, sin embargo, de un concepto nuevo ya que Steiner (1975: 45) lo utilizó poniendo el énfasis en el aspecto lingüístico. Boechner amplía, no obstante, los límites de su actuación y le da un enfoque nuevo al considerar al mediador como algo mucho más que un simple traductor o intérprete.

En este punto surgen de nuevo divergencias a la hora de definir el papel del traductor o intérprete como mediador cultural. Dos son las posturas que cabe reseñar: la primera es la de aquellos autores como Kondo (1990: 59) o Roy (1993) que tratan de poner límites a la intervención del intérprete y que consideran que, si conseguir transmitir el significado implica trabajar con ideas y no con palabras, entonces no admiten que tal hecho sea una traducción. La segunda postura es la de autores como Brislin (1987) o Knapp-Potthof y Knap (1981: 183), quienes defienden la visibilidad del intérprete como tercer elemento presente, e incluso apuntan que, dentro de ciertos límites, el mediador cultural puede desarrollar sus propias iniciativas y ser más visible.

En resumen, existen también posturas diferentes acerca del papel y de los deberes y derechos de estos intermediarios lingüísticos. No existe ni siquiera una terminología única, pero en lo que no parece haber discusión es en la necesidad de dar información y formación específica a estas personas bilingües, trilingües o políglotas que son actualmente los intermediarios entre dos comunidades que no pueden entenderse utilizando la lengua. Son escasos los recursos disponibles en algunas combinaciones de lenguas y escasos la oferta de formación y los medios para acceder a ella. Como ejemplo, solo en el caso de la Comunidad de Madrid, una de las zonas con mayor índice de inmigrantes, se podrían citar los cursos sobre mediación interlingüística que ofrece la EMSI y el Programa de Formación en Traducción e 
Interpretación en los Servicios Públicos que se imparte en la Universidad de Alcalá en varios pares de lenguas, seminarios que organiza la Escuela de Traductores de Toledo que, aunque perteneciente a otra comunidad autónoma, es lugar habitual de encuentros de traductores e intérpretes especialmente en árabe, y algún que otro curso o seminario o taller esporádico organizado por las más variadas organizaciones o instituciones, pero sin continuidad. Sin duda, se trata de una asignatura pendiente en el complejo entramado de las relaciones interculturales.

\section{La figura del intérprete como mediador}

El intérprete es el medio de la comunicación universal, un elemento imprescindible en un mundo de intercambios. La función que desempeña el intérprete supone convertir el mensaje original que produce un emisor en el mismo mensaje en el idioma del receptor. Esto no solamente requiere un amplio dominio de ambas lenguas, también son necesarios conocimientos extralingüísticos (culturales, situacionales...), una buena memoria, una gran capacidad de síntesis y un gran sentido común.

Aunque el traductor y el intérprete necesitan manejar en líneas generales las mismas características y habilidades, también deben reconocerse ciertos rasgos específicos diferentes. Entre éstos, los más comunes son los siguientes: cultura general, dominio de las dos lenguas, reconocimiento de diferencias lingüísticas y culturales, conocimiento de términos específicos, curiosidad intelectual, objetividad, fidelidad al texto o discurso original, así como posesión de un código de conducta propio.

Por un lado, los traductores son mediadores en otro sentido; son lectores privilegiados del texto en lengua original. A diferencia del lector normal del original o de la versión, el traductor lee para producir, descodifica para volver a codificar. Dicho de otro modo, el traductor utiliza como materia prima para el proceso traslaticio información que normalmente constituiría el producto y, por tanto, el final del proceso lector. La elaboración interpretativa, en consecuencia, será probablemente más profunda, menos espontánea que la del lector ordinario; y la comprensión de un fragmento del texto se beneficiará de las conclusiones que deriven de la lectura de las posteriores partes de aquél.

La posibilidad de sacarle provecho a la retrospección es común al traductor y al intérprete consecutivo; pero de ello carece el intérprete simultáneo, cuya elaboración del texto entrante debe ceñirse por completo al texto de salida.

Por otro lado, hay una serie de habilidades más requeridas en la actividad del intérprete que en la del traductor, como una buena memoria retentiva, que le permita recordar con rapidez todo tipo de expresiones y fórmulas para poder asegurar la calidad de la interpretación; y mayor agilidad en los diferentes tipos de interpretación (simultánea, consecutiva y de enlace) que implican a su vez simultaneidad o posterioridad y espontaneidad o no espontaneidad en la reformulación. Al mismo tiempo, el intérprete también necesita cierta habilidad para identificar rápidamente estilos y pasar de uno a otro con bastante facilidad, así como una buena capacidad de síntesis y concisión para evitar la redundancia. 
En cuanto a las competencias del mediador cultural, nos encontramos con unas características propias de esta profesión. Por un lado, Taft (1981: 53), quien define al mediador cultural como la persona que facilita la comunicación, el entendimiento y la acción entre personas o grupos que poseen una lengua y cultural diferente y que deben ser por lo tanto biculturales, detalla las siguientes características:

- Conocimiento histórico, social y cultural: historia, tradiciones, costumbres, valores y tabúes, sus gentes, su forma de relacionarse, etc.;

- Habilidades comunicativas: dominio no sólo del lenguaje escrito y oral sino de otro tipos de comunicación: lenguaje corporal, gestos, signos, símbolos, etc.;

- Habilidades técnicas adaptadas a la situación: saber utilizar el ordenador, saber comunicar por teléfono, vestir adecuadamente, conocer su entorno y cómo desplazarse, etc.;

- Habilidades sociales: conocimiento de las normas que rigen las relaciones sociales y las reacciones emocionales, capacidad de auto-control según requiera la situación y la cultura.

Por otro lado, autores como Corsellis (2003: 71) consideran que, además de los principios básicos de los códigos de conducta, las características o elementos que los profesionales que trabajan en esos entornos deben poseer o desarrollar son las siguientes:

- Confidencialidad: respetar el derecho a la vida privada de los otros;

- Imparcialidad: no tomar partido por ninguna de las partes;

- Exactitud/ Fidelidad: asegurarse de que el mensaje es fiel al original y apropiado en el nuevo contexto cultural;

- Integridad: ser honrado con uno mismo y su capacidad o habilidad a la hora de aceptar un trabajo de I/T

Por último, la intermediación cultural implica ciertas particularidades que tienen que ver con la misma naturaleza de la actividad y con el tipo de usuarios a los que se presta servicio (Valero 2006):

- Los usuarios en situaciones difíciles con los que el intérprete puede compartir ciertos rasgos (datos biográficos, experiencias, el pertenecer a una etnia, etc.);

- Los usuarios que han vivido situaciones de violencia, sufrido torturas o pérdidas de familiares y amigos (como es el caso de muchos solicitantes de asilo);

- Los usuarios con un estado psicológico y emocional muy deteriorado y cuyas conversaciones suelen tener un contenido predominantemente negativo;

- Los usuarios no pueden recibir ayuda directa del intérprete, lo que frecuentemente suele exigir una implicación activa, entonces, parece lógico pensar que estas personas que sirven de enlace entre dos lenguas y culturas deben poseer una alta estabilidad emocional para llevar a cabo con éxito tal tarea de intermediario. 
En definitiva, se debe poseer un alto grado de sensibilidad intercultural que permita negociar el significado entre ambas culturas y ser capaz de transmitirlo a los miembros de la otra comunidad en la otra lengua.

\section{Mediación intercultural: ámbito profesional}

Comprendemos que la mediación intercultural es una forma de comunicación que se da en cualquier sociedad multicultural. Bien es cierto que no existe un acuerdo generalizado sobre su campo de acción. Según Wadensjö (1998: 33), la T/ISSPP se refiere a un tipo de interpretación que tiene lugar en el ámbito de los servicios públicos para facilitar la comunicación entre el personal oficial y los usuarios: en las comisarías, oficinas de inmigración, centros de ayuda social y de salud, escuelas o servicios similares. En cambio, mientras Wadensjö limita su campo de acción a las relaciones de los habitantes de una nación con las instituciones oficiales, Mikkelson (1996: 126) propone una definición mucho más amplia y considera que T/ISSPP supone una actividad que permite que personas que no hablan lengua/s oficial/es del país en el que se hallan puedan comunicarse con los proveedores de servicios públicos con el fin de facilitar el acceso igualitario a los servicios legales, sanitarios, educativos, oficiales y sociales.

En esta misma línea encontramos otros acercamientos que ponen el énfasis en las desigualdades existentes entre los dos grupos. Es decir, se trata de establecer la comunicación con un público específico que responde a una minoría cultural y lingüística, poseedora de un nivel educativo y adquisitivo generalmente inferior al de la mayoría y que, con frecuencia, desconoce o no domina la nueva realidad social del país en el que se encuentra. A ello se suma, tal y como Roberts (1997: 12) indicaba, el hecho de que la cultura del grupo minoritario- e incluso más que una lengua- no es siempre comprendida por el grupo mayoritario que organiza y ofrece los servicios a dicho cliente.

Otros autores hablan de que la delimitación de su campo de acción implica una tarea compleja y de difícil solución tal y como demuestran las investigaciones empíricas y las publicaciones que van apareciendo en número creciente, y que se basan en el análisis del discurso del intérprete o de textos traducidos para una comunidad específica. En ellas (Berk-Seligson 1900, Roy 1992, Wädensjö 1992, Englund-Dimitrova 1997, Valero 2003b, Morelli 2005) se demuestra que el intérprete no lleva a cabo un mero trasvase lingüístico sino que une funciones de coordinación, mediación o negociación de significados culturales o sociales. El problema está en encontrar el límite preciso de esa intervención. Ello ha dado lugar también a diferentes concepciones filosóficas y prácticas que van desde aferrarse al estricto trasvase lingüístico hasta la mediación o defensa activa del usuario perteneciente a la minoría. Tanto si nos situamos en uno como en otro extremo las consecuencias pueden acarrear resultados perjudiciales para los interlocutores, sobre todo para la parte más débil (Pöchhecker y Kadrid 1999, Cambridge 2002). 


\section{Conclusión}

Queremos dejar constancia de que a pesar de que existan practicantes de la mediación intercultural, queda mucho camino por recorrer para lograr hacer de la interpretación en los SSPP una profesión equiparable al intérprete de conferencias. Hoy por hoy es una profesión emergente en España y en otros países del sur de Europa debido a la llegada constante de personas de otras culturas en los últimos años, como ya avanzábamos en los epígrafes anteriores. Por ello, esperamos, a través de este artículo, no solo haber expresado que el intérprete se halla en el centro del proceso dinámico de comunicación, como ya sabemos, sino haber puesto de manifiesto que existe la figura del mediador intercultural con características propias que la definen como profesión.

Asimismo, dar a conocer que en aquellos países en los que llevan años buscando la profesionalización de sus practicantes, las trabas son numerosas. Son los factores económicos, sociales y educativos los que, a nuestro juicio, más barreras plantean. Para llegar a este punto hace falta que el propio intérprete cobre conciencia positiva de su labor y que la sociedad dote de prestigio social al intérprete como mediador, que el intérprete posea no solo la capacidad como bilingüe, sino una perspectiva bicultural. Los intérpretes median entre culturas, lo cual incluye las ideologías, los sistemas morales y las estructurales sociopolíticas, con el objetivo de vencer las dificultades que atraviesa el camino que lleva a la transferencia de significado. Lo que tiene valor como signo en una comunidad cultural puede estar desprovisto de significación en otra, y el intérprete se encuentra inmejorablemente situado para identificar la disparidad y tratar de resolverla.

\section{Referencias bibliográficas}

Berk Seligson, S., The bilingual courtroom: court interpreters in the judicial process. Chicago: University of Chicago Press 1990.

Boechner, St. (ed.), The Mediating Person: Bridges between Cultures. Cambridge: Schenkman 1981.

Brislin, Richard W., Cross-cultural encounters: face to face interaction. Pergamon: Oxford, 1987.

CAMBRIDGe, J., «Interlocutor roles and the pressures on interpreters», en: VALERo Garcés, C. / Mancho BARÉs, G. (eds.), Nuevas necesidades para nuevas realidades. Madrid: Universidad de Alcalá 2002, 119-123.

CAmbridge, J., «Unas ideas sobre la interpretación en los centros de salud», en: VAlero Garcés, C. (ed.), Traducción e interpretación en los Servicios Públicos. Contextualización, actualidad y futuro. Granada: Comares 2003, 3-30.

CoRsellis, A., «Formación de los proveedores de servicios públicos para trabajar con intérpretes y traductores. Habilidades y competencias interculturales», en: VALERO GARCÉs, C. (ed.), Traducción e interpretación en los Servicios Públicos. Contextualización, actualidad y futuro. Granada: Comares 2003, 180-191.

CoRsellis, A., «Creating a professional context for public service interpreters and translators», en: VAlero GARCÉs, C. / MANCho BARÉs, G. (eds.), Nuevas necesidades para nuevas realidades. Madrid: Universidad Alcalá de Henares 2002, 182-186. 
ENGLUND Dimitrova, B., «English Degree of interpreter responsibility in the interaction process in community interpreting», en: CARR, S. A. / ROBERTS, R. / Dufour, A. / STEYN, D. (eds.), The critical link: interpreters in the community. Amsterdam: Benjamins 1997, 147-164.

KnAPP-PotThoff, A. / KNAPP, K., «The man (or woman) in the middle: discoursal aspects of non-professional interpreting», en: BoEchner, ST. (ed.), The Mediating Person: Bridges between cultures. Cambridge: Schenkamn 1981, 181-201.

KonDO, M., "What conference interpreters should not be expected to do», The Interpreter's newsletter 1990.

LAMBERT, S. / MOSER-MERCER, B., Empirical research in simultaneous interpretation. Reino Unido: John Benjamins 1994.

Mason, I., «Dialogue lnterpreting», Special issue of The Translator, 1999.

MikKelson, H., «Community Interpreting. An Emerging Profession», Interpreting 1, 1996.

Morelli, M., La intepretación español-italiano: planos de ambigüedad y estrategias. Granada: Comares-Interlingua 2005.

PöchHACKER, F., «Getting organized: The evolution of community interpreting», Interpreting, 4, 1 (2002), 125-141.

PÖchHACKer, F. / KADRIC, M., «The Hospital Cleaner as Healthcare Interpreter», The Translator, 1999.

Phelan, M., «The Interpreter's Resource», Manchester Multilingual Matters 2001, 20-38.

RoBerTs, R., "Community Interpreting today and tomorrow», en: CARR, S. et al. (eds), The Critical Link 1: interpreters in the community. Amsterdam/Filadelfia: John Bejamins 1997, 7-28.

RoY, C., «A sociolinguistic analysis of the interpreter's role in simultaneous talk in face-toface interpreted dialogue», Sign Language Studies 74 (1992), 21-61.

SteIner, G., After Babel: Aspects of Language and Translation. Oxford: OUP 1975.

TAFT, R., «The role and personality of the mediator», en: BoECHNER, S. (ed.), The Mediating Person: Bridges between cultures. Cambridge: Schenkman 1981.

VAlero Garcés, C., Formas de mediación Intercultural. Traducción e Interpretación en los SSPP. Conceptos, datos, situaciones y práctica. Granada: Comares-Interlingua 2006.

Valero Garcés, C. (ed.), Traducción e interpretación en los Servicios Públicos. Contextualización, actualidad y futuro. Granada: Comares 2003.

WADENSJÖ, C., Interpreting as Interaction. Harlow / Essex: Addison Wesley Longman Limited, 1998.

WADENSJÖ, C., Interpreting as Interaction: On Dialogue-Interpreting in Immigration Hearings and Medical Encounters. Linkoping: Linkoping University 1992. 